Article

\title{
Effect of Carbon Content and Elements Mo and V on the Microstructure and Properties of Stainless Steel Powder Surfacing Layer
}

\author{
Taixu Xu ${ }^{1}$, Chongyi Wei ${ }^{2}$, Xiao Han ${ }^{1}$, Jihui Liu ${ }^{1}$, Zhijun He ${ }^{1, *}$ and Nan Lü ${ }^{1, *}$ \\ 1 School of Materials and Metallurgy, University of Science and Technology Liaoning, Anshan 114051, China; \\ xutaixu@126.com (T.X.); tophanxiao@126.com (X.H.); gtyj66@126.com (J.L.) \\ 2 Angang Group Iron and Steel Research Institute, Anshan 114009, China; agweichongyi@163.com \\ * Correspondence: hezhijun@ustl.edu.cn (Z.H.); lvnan9999@ustl.edu.cn (N.L.)
}

Received: 11 March 2020; Accepted: 7 April 2020; Published: 9 April 2020

\begin{abstract}
This study evaluated the effect of an increase in carbon content and the presence of the elements Mo and V on the microstructure and properties of the surfacing layer of stainless steel powder for knives and scissors production. Various types of high-quality stainless steel powder $\left(5 \mathrm{Cr}_{13}, 8 \mathrm{Cr}_{13}\right.$, and $\left.8 \mathrm{Cr}_{13} \mathrm{MoV}\right)$ were deposited on the surface of low-grade stainless steel used to produce knives and scissors $\left(2 \mathrm{Cr}_{13}\right)$. The microstructure, comprehensive hardness, wear resistance, impact toughness, and corrosion resistance of the stainless steel powder surfacing layers were tested and analyzed. Results indicate that the increase in carbon content and the presence of Mo and V improve the comprehensive hardness and wear resistance of the stainless steel powder surfacing layer, and both exert the superposition effect. However, the increase in carbon content and the presence of Mo and V slightly influence the impact toughness of the surfacing layer. In addition, the increase in carbon content significantly reduces the corrosion resistance of the surfacing layer. This adverse effect is reduced when Mo and V exist. Other advantages of the presence of Mo and V in the stainless steel powder surfacing layer include the refinement of grain size, reduction of carbide particle size, and improvement of the metallurgical bonding of the surfacing layer and the matrix.
\end{abstract}

Keywords: plasma surfacing layer; stainless steel powder; microstructure; comprehensive performance

\section{Introduction}

Plasma surfacing is one of the widely used methods for steel surface strengthening [1-3] owing to several advantages, including the wide variety of surfacing materials, low dilution rate, and high production efficiency $[4,5]$. Compared with thermal spraying and chemical deposition, plasma surfacing increases the bonding force of the surfacing layer formed with the matrix, resulting in metallurgical bonding and a thickness larger than that obtained using other methods [6-11]. The performance of the surfacing layer is closely linked to the material from which it is made. Numerous studies have selected hard alloy powders as the surfacing material, including iron-based, cobalt-based, and nickel-based powders [12-14]. The obtained surfacing layer exhibits high hardness, good wear resistance, and corrosion resistance, which can effectively strengthen the comprehensive performance of the matrix surface [15-19]. However, studies are rarely reported on the application of high-quality stainless steel powder as the surfacing material for knife and scissors production.

Stainless steel materials used to manufacture knives and scissors are mainly divided into (i) low-grade materials with low and medium carbon content and (ii) high-grade materials with high content of carbon and alloy elements (Mo, Ti, V, and W). Owing to high costs, the use of high-grade materials is mostly limited to surgical tools, high-grade kitchen knives, and high-grade 
barber tools, which are seldom used in daily life. Therefore, to manufacture high-quality knives and scissors that can be used by the general public, this study explores a method to produce such instruments by plasma surfacing. The surfacing layer obtained by plasma surfacing can achieve large thickness $[20,21]$. This characteristic is used for surfacing powders of high-grade materials for knife and scissors production on the surface of massive low-grade materials for knife and scissors production. The composite material is then longitudinally cut. The thicker surfacing layer is directly used to produce the edge of knives and scissors, while the matrix (low-grade materials) is used to produce the body of knives and scissors. The method belongs to local strengthening of knives and scissors. The advantage of this method is that only the edge of a knife or scissors is mainly forced and abraded during use [22-24]; most high-grade materials are in an idle state of inaction. Limiting the use of high-grade materials to the production of the edge of a knife or scissors can not only meet the requirements for knife and scissors production but also reduce waste (of high-quality materials) and limit costs. However, no studies have been reported on surfacing high-quality stainless steel powder for knife and scissors production, and no methods have been developed to evaluate the microstructure and properties of the surfacing layer of high-quality stainless steel powder for such production.

This study mainly aims to explore the microstructure and properties of the surfacing layer of high-quality stainless steel powder for knife and scissors production, to identify excellent plasma surfacing materials that can be used to make the edge of knives and scissors, and to provide a theoretical basis for further research. This study evaluates the effects of an increase in carbon content and the presence of Mo and V on the microstructure and the effects of carbide in the surfacing layer of high-quality stainless steel powder for knife and scissors production. The hardness, wear resistance, toughness, and corrosion resistance of the surfacing layer are comprehensively analyzed. Compared with the knife and scissors material used as the matrix, among the currently selected surfacing materials, the optimal surfacing material that can be used to produce the edge for knives and scissors is analyzed.

\section{Experimental}

\subsection{Experimental Materials}

The matrix material used in this study is $2 \mathrm{Cr}_{13}$ low-carbon martensitic stainless steel, measuring $150 \mathrm{~mm} \times 150 \mathrm{~mm} \times 50 \mathrm{~mm}$. The results of the composition analysis of the matrix material are listed in Table 1. The surfacing materials used include $5 \mathrm{Cr}_{13}, 8 \mathrm{Cr}_{13}$, and $8 \mathrm{Cr}_{13} \mathrm{MoV}$ martensitic stainless steel spherical in form and measuring 50-100 $\mu \mathrm{m}$. The results of the composition analysis of the three kinds of surfacing materials are listed in Table 2.

Table 1. Chemical composition of the matrix material in the present study (wt\%).

\begin{tabular}{ccccccccc}
\hline $\mathbf{C}$ & $\mathbf{S i}$ & $\mathbf{M n}$ & $\mathbf{P}$ & $\mathbf{N i}$ & $\mathbf{C r}$ & $\mathbf{M o}$ & $\mathbf{V}$ & $\mathbf{F e}$ \\
\hline 0.20 & 0.40 & 0.25 & 0.025 & 0.12 & 13.00 & - & - & Bal. \\
\hline
\end{tabular}

Table 2. Chemical composition of the surfacing materials in the present study (wt\%).

\begin{tabular}{cccccccccc}
\hline Grade & $\mathbf{C}$ & $\mathbf{S i}$ & $\mathbf{M n}$ & $\mathbf{P}$ & $\mathbf{N i}$ & $\mathbf{C r}$ & $\mathbf{M o}$ & $\mathbf{V}$ & $\mathbf{F e}$ \\
\hline $5 \mathrm{Cr}_{13}$ & 0.52 & 0.60 & 1.00 & 0.035 & 0.60 & 13.00 & - & - & Bal. \\
$8 \mathrm{Cr}_{13}$ & 0.80 & 1.00 & 1.00 & 0.045 & 0.15 & 13.00 & - & - & Bal. \\
$8 \mathrm{Cr}_{13} \mathrm{MoV}$ & 0.80 & 1.00 & 1.00 & 0.045 & 0.15 & 13.00 & 0.20 & 0.20 & Bal. \\
\hline
\end{tabular}

\subsection{Scheme of Surfacing Technology}

Before surfacing, the surfacing zone of matrix is polished by sandpaper to remove the rust layer and oxide film; then the residual oil is cleaned by acetone, and is preheated in a muffle furnace for $1 \mathrm{~h}$ at $350-400{ }^{\circ} \mathrm{C}$. The surfacing powder of $5 \mathrm{Cr}_{13}, 8 \mathrm{Cr}_{13}$ and $8 \mathrm{Cr}_{13} \mathrm{MoV}$ is placed in an oven at $150-200{ }^{\circ} \mathrm{C}$ 
for $1 \mathrm{~h}$. The three types of stainless steel powder were surfaced on the matrix with the thickness of the surfacing layer in the $10-15 \mathrm{~mm}$ range. The detailed process parameters are listed in Table 3 . After surfacing, the composite materials were placed in a muffle furnace that had been heated to $700{ }^{\circ} \mathrm{C}$ over time and cooled with the furnace to prevent the surfacing layer from cracking due to an excessive cooling rate.

Table 3. Plasma surfacing parameters.

\begin{tabular}{cccccccc}
\hline Current A & Voltage V & $\begin{array}{c}\text { Powder } \\
\text { Feeding } \\
\text { Rate } \\
\text { g/min }\end{array}$ & $\begin{array}{c}\text { Distance } \\
\text { of } \\
\text { Surfacing } \\
\mathbf{m m}\end{array}$ & $\begin{array}{c}\text { Stepping } \\
\text { Width } \\
\mathbf{m m} / \mathbf{m i n}\end{array}$ & $\begin{array}{c}\text { Plasma } \\
\text { Torch } \\
\text { Speed, } \\
\mathbf{m m} / \mathbf{m i n}\end{array}$ & Shielding & $\begin{array}{c}\text { Plasma } \\
\text { Gas }\end{array}$ \\
\hline $140-160$ & $30-40$ & $50-70$ & $15-25$ & $3-7$ & $260-290$ & Argon & Argon \\
\hline
\end{tabular}

The composite material with $10 \mathrm{~mm}$ thickness is longitudinally cut (the cutting line in Figure 1a by wire-electrode cutting after treatment with low-rate cooling. The composite is then longitudinally cut with a wire-electrode with cutting thickness of $10 \mathrm{~mm}$. The chip composite after cutting is the prototype of the cutter blank. As shown in Figure 1b, the surfacing layer part can be used as the cutting edge and the matrix part can be used as the blade. Samples are taken at the interface of the surfacing layer and the matrix by wire-electrode cutting. The samples, measuring $10 \mathrm{~mm} \times 10 \mathrm{~mm} \times 10 \mathrm{~mm}$, were used for optical microscope (OM) observation, scanning electron microscope (SEM) observation and electrochemical corrosion test. The samples with dimension $55 \mathrm{~mm} \times 10 \mathrm{~mm} \times 10 \mathrm{~mm}$ were used for impact testing. The sampling position is shown in Figure $1 \mathrm{~b}$.

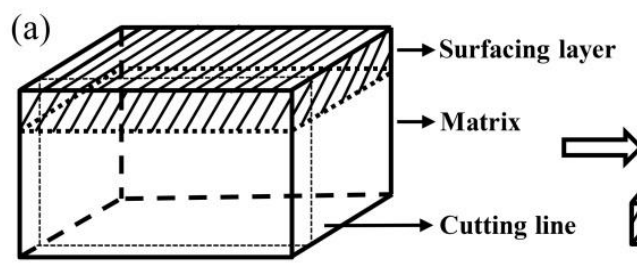

(b)

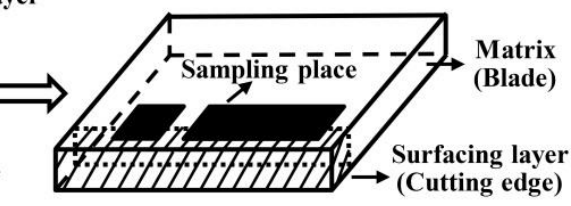

Figure 1. Cutting and sample selection. (a) position of cutting line in composite surfacing materials;

(b) sampling zone in composite surfacing materials.

\subsection{Test Methods and Equipment}

The surface of the surfacing layer and the composite cross section of the matrix and surfacing layer were gradually sanded to \#2000, and polished to the mirror with $1.5 \mu \mathrm{m} \mathrm{Al}_{2} \mathrm{O}_{3}$. SEM was conducted using the JSM-6480LV (Japan electron optics laboratory, Beijing, China) to observe the carbide of the surface and cross-section of the surfacing layer, under $20 \mathrm{kV}$ work voltage. An etching solution was obtained by mixing $5 \mathrm{~g}$ of picric acid, $50 \mathrm{~mL}$ of hydrochloride, and $50 \mathrm{~mL}$ of ethanol to corrode the surface of the surfacing layer. The surface morphology of the surfacing layer after corrosion was observed under a ZEISS optical microscope (Carl Zeiss, Shanghai, China), and the SEM was used to collect energy-dispersive X-ray spectroscopy (EDS) of the grain boundary. Thermo-calc software was used to analyze the precipitation of carbide in three types of surfacing layer.

A Rockwell hardness tester (Shanghai Lianer, Shanghai, China) was used to evaluate the macrohardness of the matrix and the three types of surfacing layer, and 50 points of each sample were measured. For the convenience of calculation, 10 points are selected to acquire the average; the results are listed in Table 4. A Vickers hardness tester (Carl Zeiss, Shanghai, China) was used to evaluate the microhardness distribution of the composite cross-sectional, and the test load was $5 \mathrm{~kg}$. The friction-and-wear tester (Lanzhou Huahui Instrument Technology, Lanzhou, China) was used to measure the wear resistance (the load is $500 \mathrm{~g}$, the test time is $60 \mathrm{~min}$, the friction radius is $3 \mathrm{~mm}$ ) and mass of both the surfacing layer and the matrix before and after the friction and wear were 
measured using a one-thousandth balance. Mass loss was also calculated; the results are listed in Table 5. In accordance with the Chinese Standard GB/T 229-2007 [25], impact testing was conducted on composite specimens measuring $55 \times 10 \times 10 \mathrm{~mm}$. The position of the V-notch is presented in Figure 2; as shown, the different composite impact tests resulted in the same thickness of the surfacing layer, and the samples are numbered as follows: \#1, $2 \mathrm{Cr}_{13} ; \# 2,2 \mathrm{Cr}_{13}+5 \mathrm{Cr}_{13} ; \# 3,2 \mathrm{Cr}_{13}+8 \mathrm{Cr}_{13}$; and \#4, $2 \mathrm{Cr}_{13}+8 \mathrm{Cr}_{13} \mathrm{MoV}$.

Table 4. The Rockwell hardness of the matrix and the different types of surfacing layer (HRC).

\begin{tabular}{cccccccccccc}
\hline $\begin{array}{c}\text { Sample } \\
\text { Types }\end{array}$ & $\mathbf{1}$ & $\mathbf{2}$ & $\mathbf{3}$ & $\mathbf{4}$ & $\mathbf{5}$ & $\mathbf{6}$ & $\mathbf{7}$ & $\mathbf{8}$ & $\mathbf{9}$ & $\mathbf{1 0}$ & Average \\
\hline $\begin{array}{c}\text { Matrix } \\
\left(2 \mathrm{Cr}_{13}\right)\end{array}$ & 42.3 & 44.5 & 44.8 & 45.3 & 41.4 & 40.0 & 42.1 & 42.1 & 43.5 & 42.5 & 42.85 \\
$5 \mathrm{Cr}_{13}$ & 41.5 & 43.2 & 41.5 & 45.2 & 44.2 & 42.2 & 43.5 & 43.2 & 44.5 & 43.0 & 43.20 \\
$8 \mathrm{Cr}_{13}$ & 56.5 & 55.5 & 54.3 & 53.7 & 57.2 & 54.2 & 55.3 & 55.0 & 56.2 & 55.1 & 55.30 \\
$8 \mathrm{Cr}_{13} \mathrm{MoV}$ & 55.6 & 56.5 & 57.5 & 57.2 & 57.0 & 56.5 & 58.5 & 55.2 & 56.5 & 56.5 & 56.70 \\
\hline
\end{tabular}

Table 5. Wear weight loss of matrix and the different surfacing layer (mg).

\begin{tabular}{ccccc}
\hline Sample Types & $\mathbf{1}$ & $\mathbf{2}$ & $\mathbf{3}$ & Average \\
\hline Matrix $\left(2 \mathrm{Cr}_{13}\right)$ & 7.4 & 7.9 & 7.5 & 7.6 \\
$5 \mathrm{Cr}_{13}$ & 7.1 & 7.5 & 7.6 & 7.4 \\
$8 \mathrm{Cr}_{13}$ & 3.1 & 3.3 & 3.5 & 3.3 \\
$8 \mathrm{Cr}_{13} \mathrm{MoV}$ & 2.2 & 1.9 & 1.9 & 2.0 \\
\hline
\end{tabular}

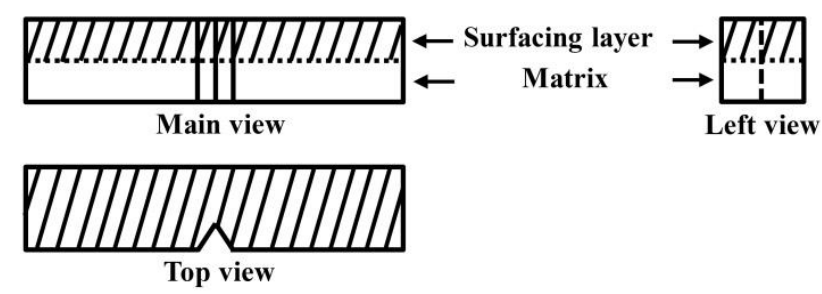

Figure 2. Chart of impact specimen.

The electrochemistry test was carried out at room temperature. The three electrode system was used in the Swiss Wantong Autolab electrochemical workstation (Metrohm, Beijing, China). The test was setup with the saturated calomel electrode as the reference electrode, the platinum electrode as the auxiliary electrode, the matrix and the three types of surfacing layers as the working electrode, and the electrolyte was $3.5 \% \mathrm{NaCl}$ aqueous solution. The effective area of the working electrode was $1 \mathrm{~cm}^{2}$, and the other non-working surfaces were sealed with organic glue. The effective surface of the working electrode was gradually sanded to $\# 1500$ and polished to the mirror. The sample was immersed in an open circuit potential for $60 \mathrm{~min}$; when the corrosion potential was basically stable, the potentiodynamic polarization curve was tested. The scanning rate of the polarization curve was $2 \mathrm{mV} / \mathrm{s}$, and the scanning range was $-0.8-0.8 \mathrm{~V}$. After the electrochemical corrosion test, SEM was used to observe the corrosion morphology of the matrix and the three types of surfacing layer under $20 \mathrm{kV}$ work voltage; the magnification was 2000 times.

\section{Test Results and Analysis}

\subsection{Effect of Carbon Content and Elements Mo and V on the Microstructure of the Surfacing Layer}

Figure 3 presents the microstructure and morphology of different surfacing layers; as shown in the figure, the surfacing layer exhibits a columnar-crystal structure. With an increase in carbon content, the grain size of the surfacing layer slightly increased, and the grain inner inclusion decreased 
significantly (Figure 3a,b). In addition, the EDS spectra at A and B show that the segregation of intercrystalline carbide increases as the carbon content in the surfacing layer increases.

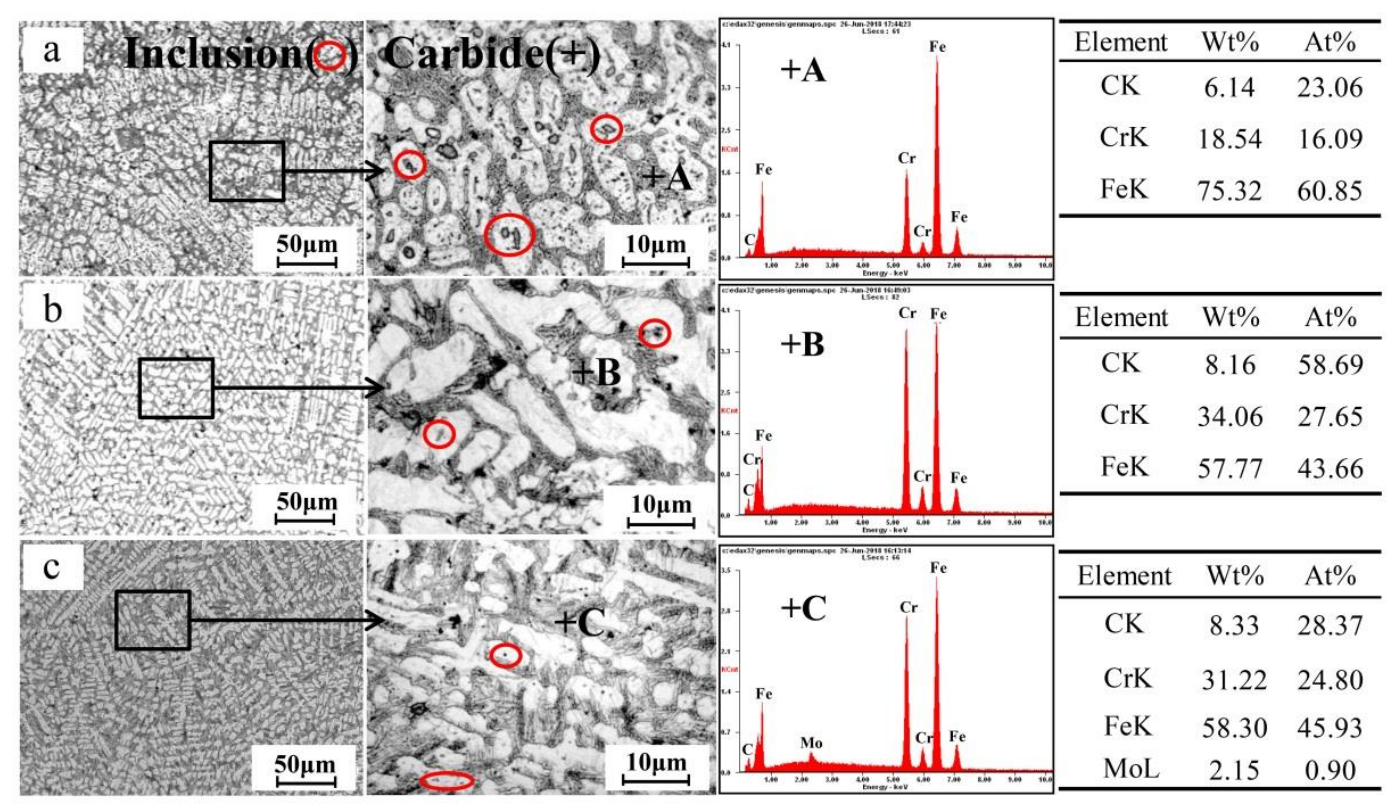

Figure 3. Microstructure and morphology of different surfacing layers and the energy-dispersive X-ray spectroscopy (EDS) energy spectrum of carbide. (a) $5 \mathrm{Cr}_{13} ;$ (b) $8 \mathrm{Cr}_{13} ;$ (c) $8 \mathrm{Cr}_{13} \mathrm{MoV}$.

The data in Table 6 can be calculated using the solid and liquidus formulas [26] in Equations (1) and (2). The composition of each surfacing layer material is listed in Table 2. The data in Table 6 indicate that an increase in carbon content leads to a crystallization temperature range of the surfacing layer and a decrease in the liquidus temperature of the surfacing layer; these results explain the aforementioned occurrence. With the cooling rate remaining the same, an increase in carbon content in the surfacing layer indicates an increase in the crystallization temperature range and a decrease in crystallization time. Therefore, the time of grain growth is sufficient, and the grain size of the surfacing layer increases. Under the same heat input, the time for liquid metal to retain good fluidity is prolonged. Intragranular inclusions can easily precipitate into grain boundaries-that is, with an increase in carbon content, intragranular inclusions markedly decrease.

Table 6. Solid and liquid phase lines of different surfacing layers $\left({ }^{\circ} \mathrm{C}\right)$.

\begin{tabular}{ccccc}
\hline Grade & $\begin{array}{c}\text { Carbide } \\
\text { Content/\% }\end{array}$ & $\mathbf{T}_{\mathbf{1}}$ & $\mathbf{T}_{\mathbf{S}}$ & $\Delta \mathbf{T}$ \\
\hline $5 \mathrm{Cr}_{13}$ & 0.52 & 1457.66 & 1307.85 & 149.81 \\
$8 \mathrm{Cr}_{13}$ & 0.80 & 1477.81 & 1250.19 & 227.62 \\
\hline
\end{tabular}

$$
\begin{gathered}
\left.\mathrm{T}_{1}=1536-90[\% \mathrm{C}]+6.2[\% \mathrm{Si}]+1.7[\% \mathrm{Mn}]+28[\% \mathrm{P}]+40[\% \mathrm{~S}]+2.6[\% \mathrm{Cu}]+2.9[\% \mathrm{Ni}]+1.8[\% \mathrm{Cr}]+5.1[\% \mathrm{Al}]\right) \\
\left.\mathrm{T}_{\mathrm{s}}=1536-415.3[\% \mathrm{C}]+12.3[\% \mathrm{Si}]+6.8[\% \mathrm{Mn}]+124.5[\% \mathrm{P}]+183.9[\% \mathrm{~S}]+4.3[\% \mathrm{Ni}]+1.4[\mathrm{Cr}]+4.1[\% \mathrm{Al}]\right)
\end{gathered}
$$

Incorporating Mo and V into the molten steel metallurgically can refine the steel structure $[27,28]$. $\mathrm{Mo}$ and $\mathrm{V}$ in the surfacing layer also play the same role. Comparison of Figure $3 \mathrm{~b}, \mathrm{c}$ indicates that the presence of Mo and V induces an evident decrease in the grain size of the surfacing layer. Dilawary found the same phenomenon in a study for the effect of an Mo element on an M2 surfacing layer; the increase of an Mo element content refines the structure of the M2 surfacing layer [29]. The reason is that both Mo and $\mathrm{V}$ are strong carbide-forming elements, which can combine with $\mathrm{C}$ to 
form carbides and pinning on the grain boundary in the surfacing layer. Such formation hinders grain growth, resulting in a refined surfacing layer.

\subsection{Effect of Carbon Content and the Elements Mo and V on Carbide Distribution in the Surfacing Layer}

The increase in carbon content and the presence of alloy elements significantly affects the distribution and size of carbide particles in the surfacing layer. The distribution and size of carbide play a decisive role in the comprehensive performance of the surfacing layer. The bonding characteristics of the surfacing layer and matrix are determined by carbide precipitation at the interface between the surfacing layer and matrix. Therefore, carbide distribution on the surface and cross-section of the surfacing layer has to be detected and analyzed.

Figure 4 presents the morphology of carbide on the surface of three surfacing layers examined by backscattered electron microscopy. As shown in the figure, carbide is entirely distributed in a network in the three surfacing layers. Consequently, a carbide network is formed for slow cooling during surfacing. Comparison of Figure $4 \mathrm{a}, \mathrm{b}$ indicates that the network size of carbide increases as the carbon content in the surfacing layer increases; moreover, the carbide particle increases in size by about 5 times of the original. The increase in size of the carbide network is attributed to carbide precipitation along the grain boundary; in addition, grain size increases with an increase in carbon content (Figure 3a,b). Therefore, an increase in carbon content leads to an increase in size of the carbide network. Comparison of Figure $5 \mathrm{a}, \mathrm{b}$ indicates that the initial precipitation temperature of the primary $\mathrm{M}_{7} \mathrm{C}_{3}$ carbide increases, whereas the initial transition temperature of $\mathrm{M}_{7} \mathrm{C}_{3}$ to $\mathrm{M}_{23} \mathrm{C}_{6}$ decreases as the carbon content increases in the surfacing layer, rendering the growth time of primary carbide sufficient. Consequently, the carbide particle size increases as carbon content increases in the surfacing layer. During plasma surfacing of Cr Mo alloy, the size of carbide in the surfacing layer increases with an increase in carbon content [30].

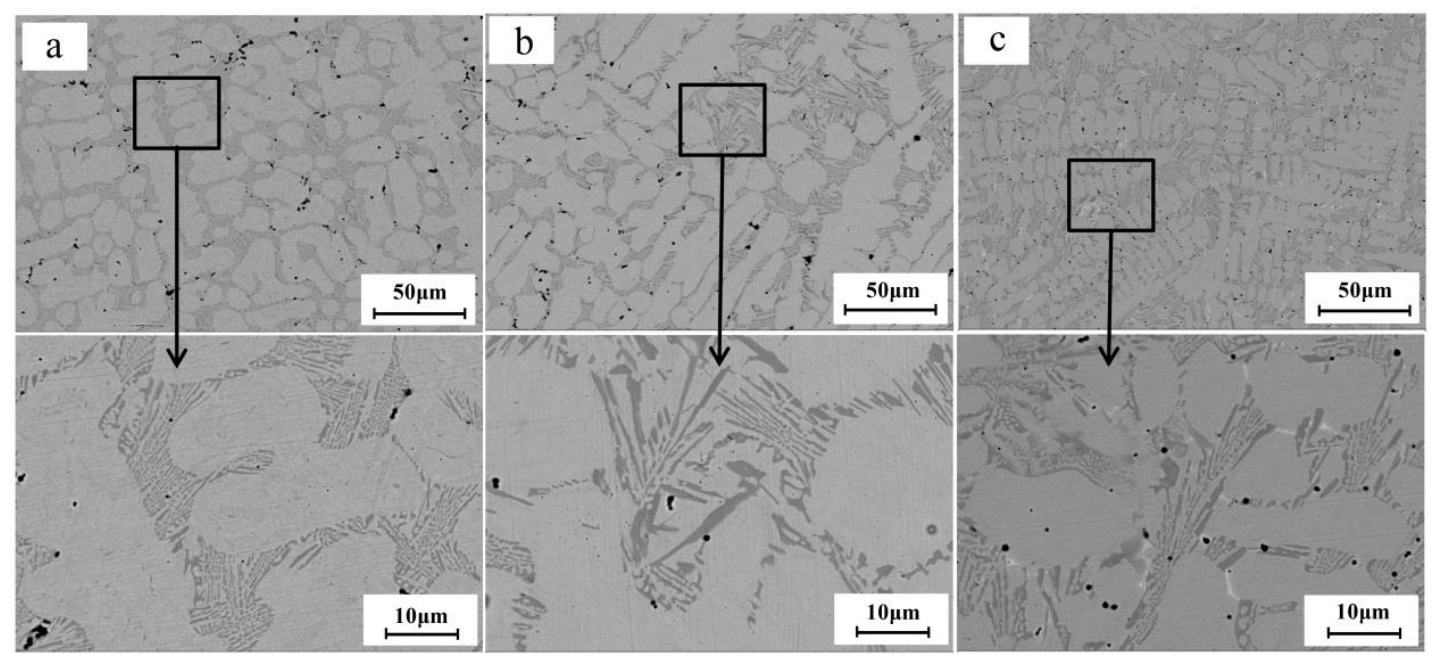

Figure 4. Surface carbide morphology of different surfacing layers. (a) $5 \mathrm{Cr}_{13} ;$ (b) $8 \mathrm{Cr}_{13} ;$ (c) $8 \mathrm{Cr}_{13} \mathrm{MoV}$. 

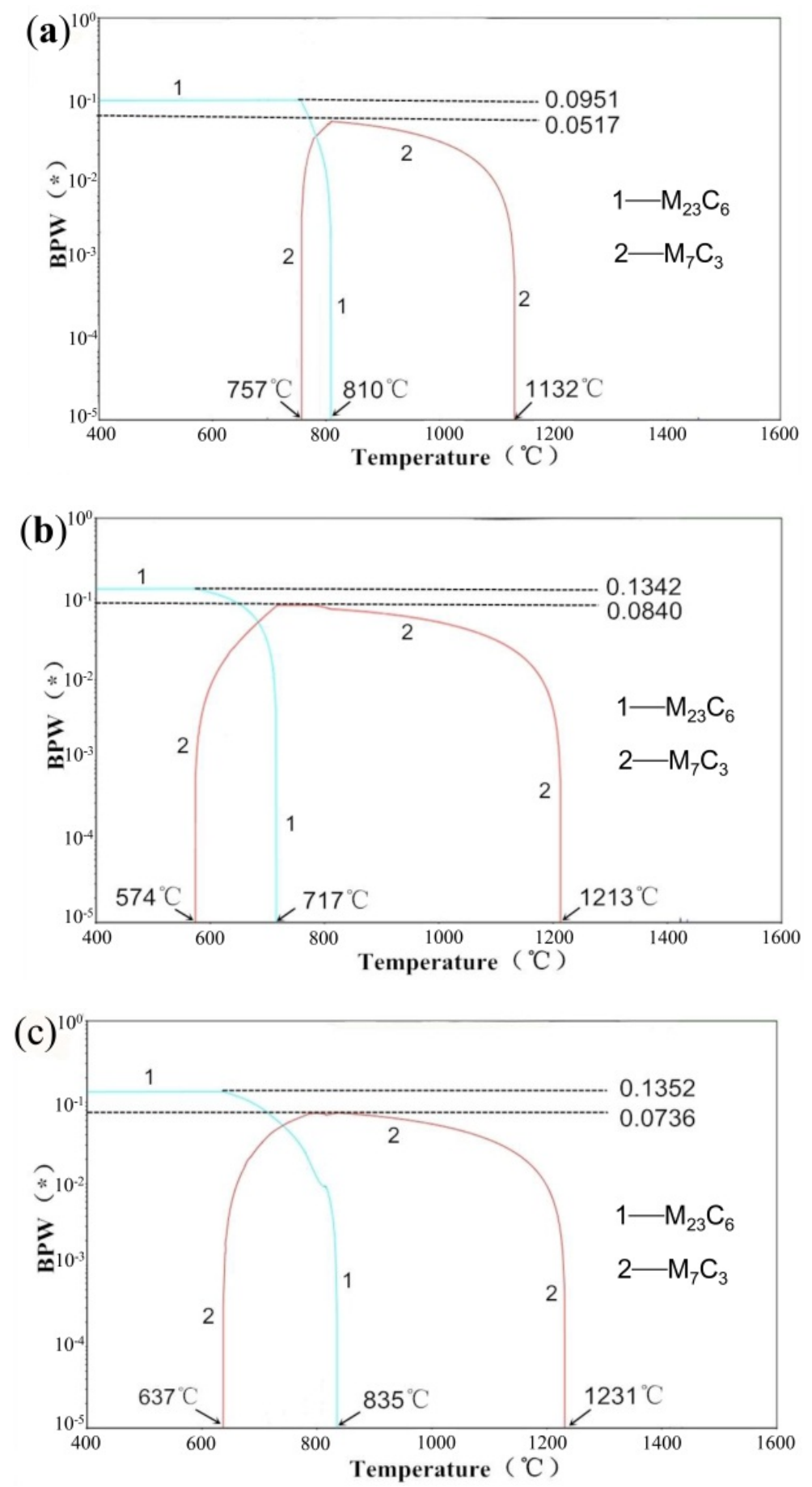

Figure 5. Type and content of carbide in different surfacing layers. (a) $5 \mathrm{Cr}_{13} ;$ (b) $8 \mathrm{Cr}_{13} ;$ (c) $8 \mathrm{Cr}_{13} \mathrm{MoV}$.

Comparison of Figure 4b,c indicates that with Mo and V, the carbide network markedly decreases in size, and the size of the carbide particles slightly decreases. This occurrence is attributed to carbide network precipitation mainly along the grain boundary, and the apparent refinement of the surfacing layer of Mo and V (Figure 3b,c). Therefore, the size of the carbide network decreases. The size of carbide particles is only slightly reduced because the presence of Mo and $\mathrm{V}$ elements can only mildly reduce the temperature range of the $\mathrm{M}_{7} \mathrm{C}_{3}$ precipitation temperature and initial transition temperature of $\mathrm{M}_{7} \mathrm{C}_{3}$ to $\mathrm{M}_{23} \mathrm{C}_{6}$ (Figure $5 \mathrm{~b}, \mathrm{c}$ ), thus shortening the growth time of carbide. 
Figure 6 shows the morphology of the surfacing layer-matrix interface. In the three figures, carbide growth in the surfacing layer extends to the matrix, and carbide precipitation occurs along the grain boundary. Thus, carbide extension of the surfacing layer can also indicate that the grain boundary of the surfacing layer extends to the matrix. The reason for this occurrence is that the surface of the matrix melts at a plasma arc temperature $>2000{ }^{\circ} \mathrm{C}$, and the surfacing layer metal and matrix metal partly melt each other. Moreover, the surfacing layer metals $\left(5 \mathrm{Cr}_{13}, 8 \mathrm{Cr}_{13}\right.$, and $\left.8 \mathrm{Cr}_{13} \mathrm{MoV}\right)$ and the matrix metal $\left(2 \mathrm{Cr}_{13}\right)$ are categorized as stainless steel. A low interfacial tension exists between them, which facilitates fusion in the liquid. Meanwhile, the occurrence is considered as metallurgical bonding, which enhances the bonding strength between the surfacing layer and the matrix. Mahdizai also found the phenomenon of grain boundaries of the surfacing layer extends to the matrix in the study of the $\mathrm{Fe}-\mathrm{Cr}-\mathrm{C}$ surfacing layer [31]. However, carbide elongation in the different surfacing layers varies. Comparison between Figure $6 \mathrm{a}, \mathrm{b}$ indicates that the degree of carbide extension to the matrix decreases with an increase in carbon content. The reason is that the grain thickens, and the extension of the grain boundary to the matrix is decreased with an increase in carbide content. Comparison of Figure $6 \mathrm{~b}, \mathrm{c}$ indicates that with the same carbide content, carbide extension to the matrix is strengthened in the presence of Mo and $\mathrm{V}$. The reason is that $\mathrm{Mo}$ and $\mathrm{V}$ can refine the grain of the surfacing layer. As shown in Figure $6 \mathrm{~b}, \mathrm{c}$, the grain size of the $8 \mathrm{Cr}_{13} \mathrm{MoV}$ surfacing layer is $5-10 \mu \mathrm{m}$, which is markedly smaller than the grain size of the $8 \mathrm{Cr}_{13}$ surfacing layer $(15-25 \mu \mathrm{m})$. Therefore, the number of grains at the interface between the surfacing layer and the matrix increases, and the number of grain boundaries extending to the matrix increases.

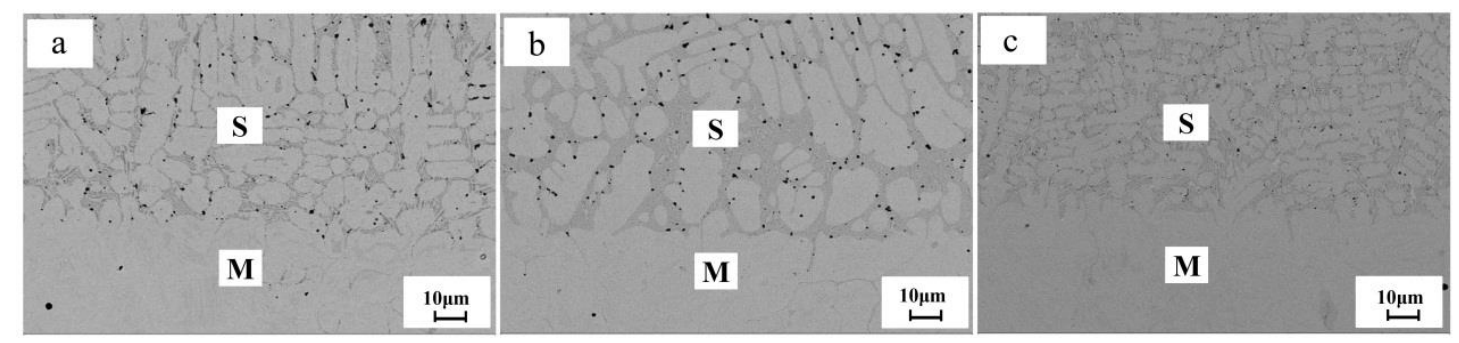

Figure 6. Morphology of carbide in the different surfacing layers. (a) $5 \mathrm{Cr}_{13} ;$ (b) $8 \mathrm{Cr}_{13} ;$ (c) $8 \mathrm{Cr}_{13} \mathrm{MoV}$. Notes: S(surfacing): M(matrix).

\subsection{Effect of Carbon Content and Elements Mo and V on the Comprehensive Properties of the Surfacing Layer}

\subsubsection{Comprehensive Hardness}

The results of the hardness testing of the different surfacing layers and matrices are shown in Figure 7a. The Rockwell hardness levels of the three types of stainless steel powder surfacing layers are higher than that of the matrix $\left(2 \mathrm{Cr}_{13}\right)$. Due to the high carbide content of the $8 \mathrm{Cr}_{13}$ and $8 \mathrm{Cr}_{13} \mathrm{MoV}$ surfacing layers, the Rockwell hardness level is significantly improved relative to that of the matrix, reaching 55.30 and $56.70 \mathrm{HRC}$. The Rockwell hardness of the $5 \mathrm{Cr}_{13}$ surfacing layer is relatively low (43.20 HRC) and similar to that of the matrix $(42.85 \mathrm{HRC})$. The closeness of the values is attributed to the slight variation in the carbide contents of the $5 \mathrm{Cr}_{13}$ surfacing layer and the matrix $\left(2 \mathrm{Cr}_{13}\right)$; in addition, high temperatures during surfacing can lead to decarbonization. Thus, an increase in the hardness of the $5 \mathrm{Cr}_{13}$ surfacing layer is not evident. 
(a)

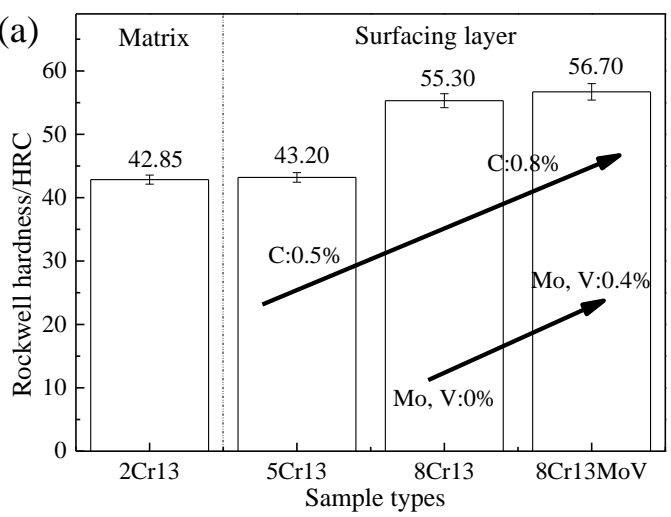

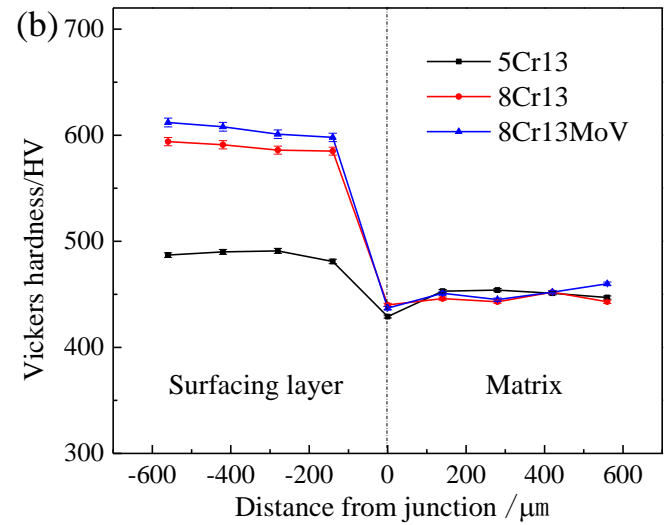

Figure 7. Hardness test of the substrate and different kinds of surfacing layers. (a) Rockwell hardness; (b) Vickers hardness.

The microhardness of the different surfacing layer cross-sections is presented in Figure $7 \mathrm{~b}$. As shown in the figure, the average microhardness levels of the $5 \mathrm{Cr}_{13}, 8 \mathrm{Cr}_{13}$, and $8 \mathrm{Cr}_{13} \mathrm{MoV}$ surfacing layers are 468,589 , and $604 \mathrm{HV}$, respectively. The change trend of the microhardness of the surfacing layer cross-section is the same as that of the Rockwell hardness test. The microhardness of the surfacing layer cross-section markedly increases with an increase in carbon content. The presence of Mo and V can slightly improve the microhardness of the surfacing layer cross-section. In addition, the microhardness at the surfacing layer-matrix interface is slightly lower than that in the surfacing layer or in the matrix. The reason may be that the surfacing layer and the matrix partly melt each other, diluting the carbon in the surfacing layer [32]. Owing to the surfacing layer-matrix interface in the interior of the material, the cooling rate is low, causing most of the carbon content to precipitate. The dissolved carbon content in the structure is relatively small, hence the low microhardness. Despite the reduced hardness of this part, the decrease falls within a small range. It can alleviate poor toughness and easy cracking induced by high hardness $[33,34]$.

Overall analysis indicates that Rockwell hardness increases with an increase in carbon content and in the presence of Mo and V. One reason is that as carbon content increases, the dissolved carbon content increases, and the amount of carbides increases in the surfacing layer (Figure 5a,b); both of them can increase the hardness of surfacing layer. On the other hand, the presence of Mo and $\mathrm{V}$ markedly refined the grain (Figure $3 b, c)$, which slightly improved the Rockwell hardness of the surfacing layer. Therefore, the comprehensive hardness of $8 \mathrm{Cr}_{13} \mathrm{MoV}$ surfacing layer is better, which is 1.38 times higher than that of the matrix.

\subsubsection{Wear Resistance}

Figure 8a presents the wear morphology of the matrix $\left(2 \mathrm{Cr}_{13}\right)$, which has obviously furrow characteristics. Microcutting and plowshare are the main mechanisms underlying material loss, together with partial adhesive wear. The wear morphological characteristics of the $5 \mathrm{Cr}_{13}$ and $8 \mathrm{Cr}_{13}$ surfacing layers are shown in Figure $8 \mathrm{~b}, \mathrm{c}$; both appear corrugated and exhibit typical adhesive wear. On the basis of the comparison between the two figures, with an increase in carbon content, corrugation size decreases. This occurrence indicates an increase in the surface hardness of the surfacing layer and is confirmed in Figure 7a. Meanwhile, Figure $8 \mathrm{~d}$ presents the wear morphology of the $8 \mathrm{Cr}_{13} \mathrm{MoV}$ surfacing layer. The figure shows no large area of abscission and deformation, indicating that the wear resistance of the $8 \mathrm{Cr}_{13} \mathrm{MoV}$ surfacing layer is higher than those of the first three. On the basis of the wear morphology of the matrix and the three types of surfacing layers we observe that the wear resistance of the surfacing layer is increased with an increase in carbon content with Mo and V in the surfacing layer. In addition, the wear resistance of the material can be characterized by measuring the mass loss of the different surfacing layers and matrix after friction-and-wear experiments. The smaller 
the wear weight loss, the higher the wear resistance. As shown in Figure 9, the wear weight loss of the surfacing layer markedly decreases with an increase in carbon content. The presence of Mo and $\mathrm{V}$ also reduces wear weight loss. The studies of Su and Qi indicated that when Mo and C simultaneously existed in the surfacing layer, the wear-resistant carbides could be formed and the wear resistance could be improved [35]; the presence of $\mathrm{V}$ decreased the size of carbide and increased the amount of the eutectic carbide and secondary carbide, which also enhanced the wear resistance of the surfacing layer [36]. Therefore, one reason for the above occurrence is that as the carbon content increases, the amount of carbide increases (Figure $5 a, b$ ), which enhances the wear resistance of surfacing layer; meanwhile the size of carbide is refined and the distribution is more dispersed (Figure $4 b, c$ ) due to the presence of Mo and V, which also increases the wear resistance of the surfacing layer. The other reason is that the wear resistance of material is proportional to its hardness, which can be described as follows $[37,38]$ :

$$
W^{-1}=K \times H
$$

where $K$ is the coefficient, $H$ is hardness, $W^{-1}$ is wear resistance. Equation (3) indicates that the higher the hardness of the material is, the less the wear damage of the abrasive particles is to the surface layer, the smaller is the degree of abscission and deformation, and the better is the wear resistance. Among the three types of surfacing layer, the hardness of the $8 \mathrm{Cr}_{13} \mathrm{MoV}$ surfacing layer is highest (Figure 7). Therefore, the wear resistance of the $8 \mathrm{Cr}_{13} \mathrm{MoV}$ surfacing layer is optimal, and compared with the matrix, it increased about 4 times.

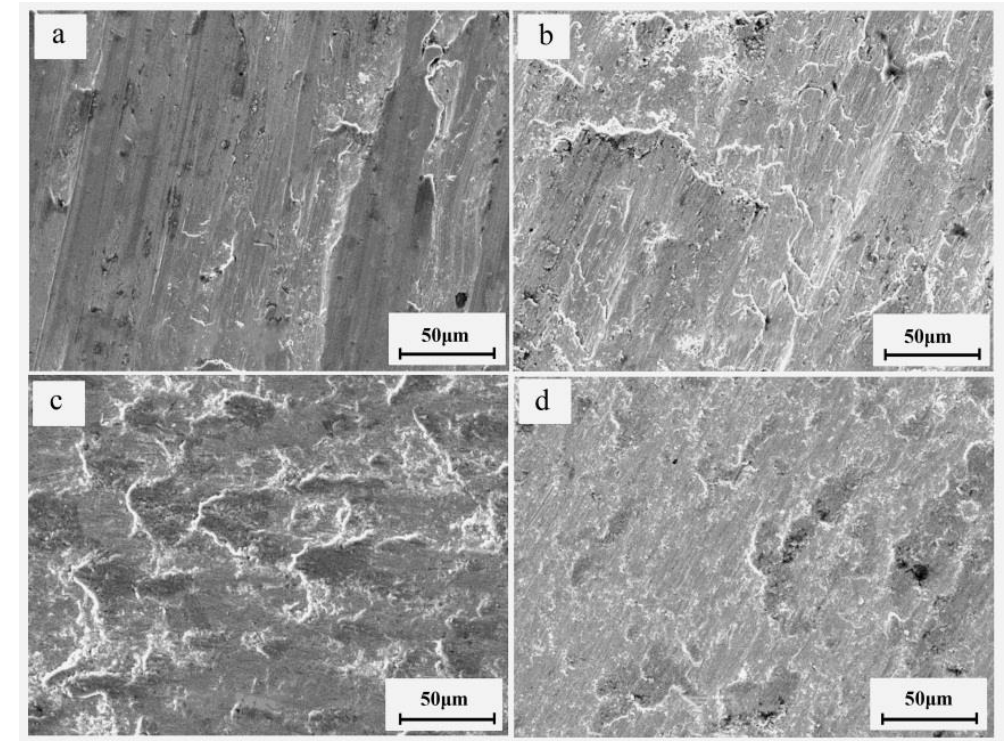

Figure 8. Morphology of different overlays after friction and wear. (a) matrix $\left(2 \mathrm{Cr}_{13}\right)$; (b) $5 \mathrm{Cr}_{13}$; (c) $8 \mathrm{Cr}_{13} ;$ (d) $8 \mathrm{Cr}_{13} \mathrm{MoV}$. 


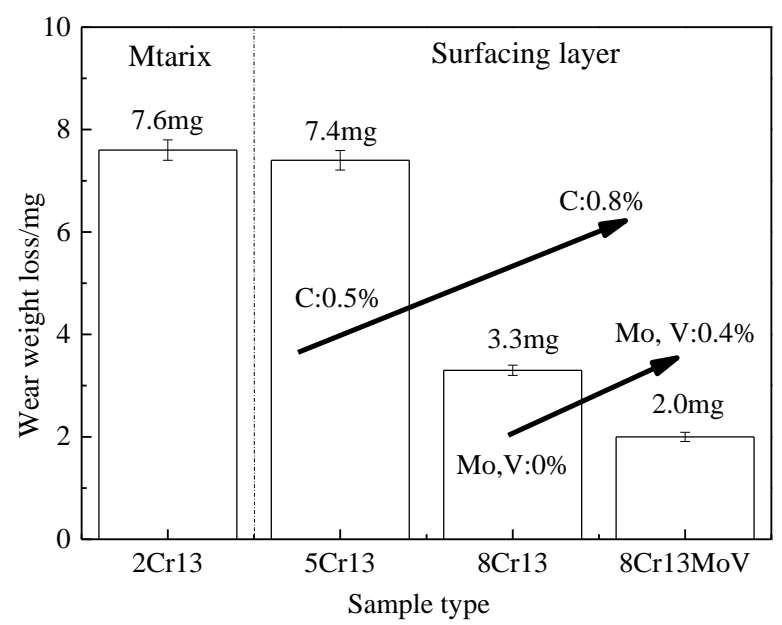

Figure 9. Wear weight loss of the matrix and the different surfacing layers.

\subsubsection{Impact Toughness}

Table 7 lists the impact energy of the matrix and the different composites. The table shows that the impact energy of the sample with different surfacing layers is greater than that of the individual matrix samples. The impact energy of the sample with the surfacing layer becomes larger with an increase in carbon content (as revealed by the comparison of \#2 and \#3), which indicates an increase in the toughness of the surfacing layer as the carbon content rises. However, the presence of Mo and $\mathrm{V}$ reduces the toughness of the surfacing layer (as shown by the comparison of \#3 and \#4). This occurrence may be related to the grain size and intergranular binding force. As shown in Figure 10, no dimple is found in the fracture of each sample, and the grain section is apparent, which shows that the fracture mode of the matrix and each surfacing layer is mainly an intergranular fracture in the brittle fracture. The impact energy of this fracture type is largely affected by the grain size [39]. Comparison of Figure 10b-e indicates that the crystal face size of the fracture is about $100 \mu \mathrm{m}$ on the matrix, and that of each surfacing layer is only about $10 \mu \mathrm{m}$. The latter is one order of magnitude smaller than the former. The smaller the grain size, the greater the number of grains and the stronger the intergranular bonding force in the same cross-sectional area. Therefore, the impact energy of the composite sample with surfacing layers (\#2,\#3, and $4 \#)$ is higher than that of the single matrix sample (\#1). The impact energies of samples \#2 and 4 are lower than that of \#3, which is mainly related to the amount of carbide precipitation. The increase of intergranular carbide weakened the intergranular bonding force. Therefore, the impact energy of the surfacing layer decreases-that is, the toughness of the surfacing layer decreases. As shown in Figure 3, the amounts of carbide precipitation at the grain boundary of the $5 \mathrm{Cr}_{13}$ and $8 \mathrm{Cr}_{13} \mathrm{MoV}$ surfacing layers are evidently larger than that of the $8 \mathrm{Cr}_{13}$ surfacing layer. Therefore, the impact toughness of $5 \mathrm{Cr}_{13}$ and $8 \mathrm{Cr}_{13} \mathrm{MoV}$ surfacing layers is lower than that of the $8 \mathrm{Cr}_{13}$ surfacing layer. The occurrence of Mo decreases the impact toughness of materials, a result also found in the study of Wu and Kong [40,41].

Table 7. Impact energy of the matrix and different composite materials $\left(\mathrm{J} \cdot \mathrm{cm}^{-2}\right)$.

\begin{tabular}{ccccc}
\hline Number & $\mathbf{1}$ & $\mathbf{2}$ & $\mathbf{3}$ & $\begin{array}{c}\text { Average Impact } \\
\text { Energy }\end{array}$ \\
\hline$\# 1$ & 6.8 & 6.6 & 7.0 & 6.8 \\
$\# 2$ & 6.9 & 6.8 & 7.0 & 6.9 \\
$\# 3$ & 7.7 & 7.7 & 8.0 & 7.8 \\
$\# 4$ & 7.1 & 6.9 & 7.0 & 7.0 \\
\hline
\end{tabular}




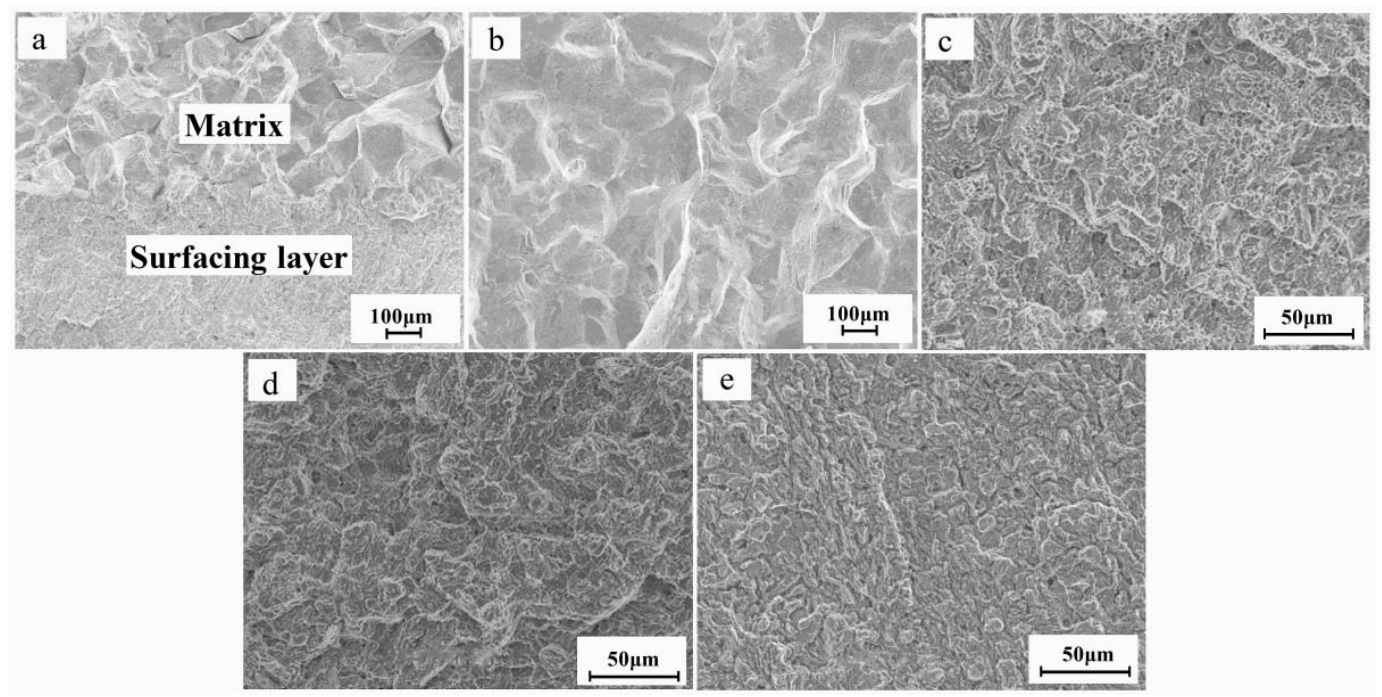

Figure 10. Impact fracture morphology of the base and different material surfacing layers. (a) fracture morphology of composite; (b) \#1; (c) \#2; (d) \#3; (e) \#4.

\subsubsection{Corrosion Resistance}

The potentiodynamic polarization curve of the different surfacing layers and the matrix in a $3.5 \% \mathrm{NaCl}$ solution is shown in Figure 11. In the figure, anodic polarization of the different surfacing layers and the matrix are blocked, and passivation is evident. The passivation behavior initially suggests improvement of the corrosion resistance of the matrix $\left(2 \mathrm{Cr}_{13}\right)$ and the surfacing layers $5 \mathrm{Cr}_{13}$ and $8 \mathrm{Cr}_{13} \mathrm{MoV}$. The passive films of the matrix $\left(2 \mathrm{Cr}_{13}\right)$ and the surfacing layers $5 \mathrm{Cr}_{13}$ and $8 \mathrm{Cr}_{13} \mathrm{MoV}$ form in the initial stages of polarization, preventing corrosion to a certain degree. In addition, the corrosion resistance of the surfacing layer can also be determined based on polarization resistance. The greater the polarization resistance in a unit area, the higher the corrosion resistance of the material. The polarization resistance can be calculated using the Stern-Geary formula [42] in Equation (4), as follows:

$$
\frac{1}{R_{\mathrm{p}}}=2.303 i_{\text {coor }}\left(\frac{1}{\beta_{\mathrm{a}}}+\frac{1}{\beta_{\mathrm{c}}}\right)
$$

where $R_{\mathrm{p}}$ is the polarization resistance, $i_{\mathrm{coor}}$ is the corrosion current, $\beta_{\mathrm{a}}$ is the anodic slope, and $\beta_{\mathrm{c}}$ is the cathodic slope. The values of the polarization resistance of the different surfacing layers and the matrix are calculated using Equation (4); the results are listed in Table 8. As shown in the table, the matrix $\left(2 \mathrm{Cr}_{13}\right)$ and the surfacing layers $5 \mathrm{Cr}_{13}$ and $8 \mathrm{Cr}_{13} \mathrm{MoV}$ have similar polarization resistance $(4.47,4.29$, and $4.48 \mathrm{k} \Omega / \mathrm{cm}^{2}$, respectively), which are significantly higher than that of the $8 \mathrm{Cr}_{13}$ surfacing layer. These results indicate that the matrix $\left(2 \mathrm{Cr}_{13}\right)$ and the surfacing layers $5 \mathrm{Cr}_{13}$ and $8 \mathrm{Cr}_{13} \mathrm{MoV}$ exhibit higher corrosion resistance. For an intuitive observation of the corrosion resistance of the different surfacing layers, the morphology of the different surfacing layer after electrochemical corrosion testing was observed by SEM (Figure 12). 


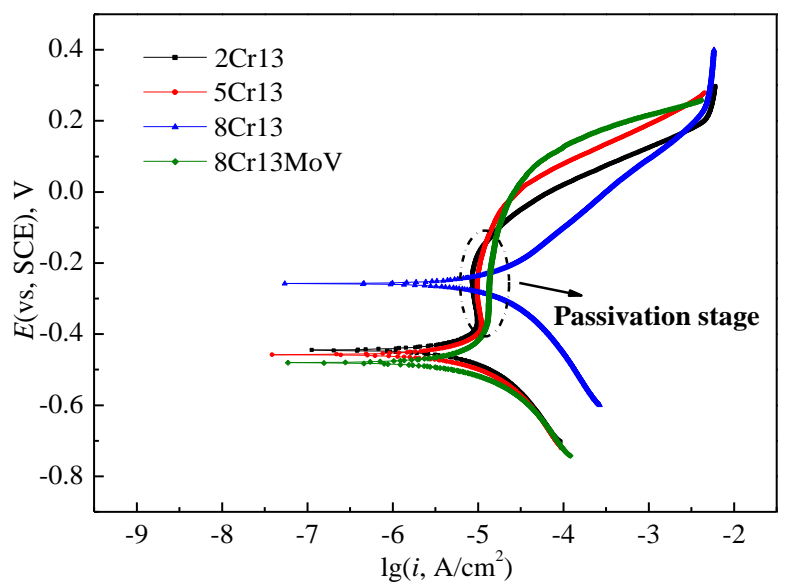

Figure 11. Potentiodynamic polarization curve of the substrate and overlay in $3.5 \% \mathrm{NaCl}$ solution.

Table 8. Electrochemical parameters related to the substrate and each surfacing layer.

\begin{tabular}{cccccc}
\hline Sample Type & $E_{\text {corr }}, \mathbf{m V}$ & $\boldsymbol{i}_{\text {coor, }} \boldsymbol{\mu A}$ & $\boldsymbol{\beta}_{\mathbf{a}}, \mathbf{m V} / \mathbf{d e c}$ & $\boldsymbol{\beta}_{\mathbf{c}}, \mathbf{m V} / \mathbf{d e c}$ & $\boldsymbol{R}_{\mathbf{p}}, \mathbf{k} \Omega / \mathbf{c m}^{2}$ \\
\hline Matrix $\left(2 \mathrm{Cr}_{13}\right)$ & -445.62 & 16.30 & 252.79 & 499.01 & 4.47 \\
$5 \mathrm{Cr}_{13}$ & -455.22 & 57.20 & 466.81 & -2679.53 & 4.29 \\
$8 \mathrm{Cr}_{13}$ & -255.46 & 28.85 & 332.83 & 276.70 & 2.27 \\
$8 \mathrm{Cr}_{13} \mathrm{MoV}$ & -476.73 & 42.18 & 332.53 & -1412.30 & 4.48 \\
\hline
\end{tabular}

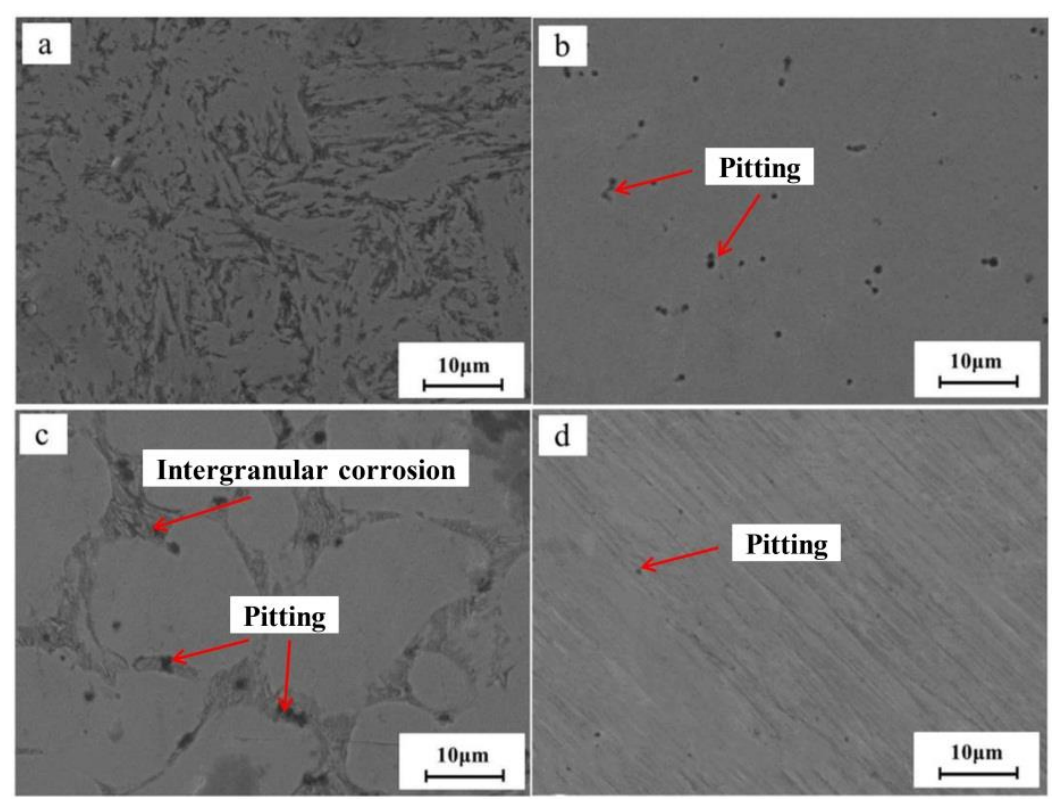

Figure 12. Electrochemical corrosion morphology. (a) matrix $\left(2 \mathrm{Cr}_{13}\right) ;(\mathbf{b}) 5 \mathrm{Cr}_{13} ;(\mathbf{c}) 8 \mathrm{Cr}_{13} ;$ (d) $8 \mathrm{Cr}_{13} \mathrm{MoV}$.

Figure 12a presents the corrosion morphology of the matrix $\left(2 \mathrm{Cr}_{13}\right)$. Corrosion starts in a small chromium-depleted zone, which is inferred as selective corrosion. Figure $12 \mathrm{~b}$,d show that both the $5 \mathrm{Cr}_{13}$ and $8 \mathrm{Cr}_{13} \mathrm{MoV}$ surfacing layers exhibit pitting morphology, with the $8 \mathrm{Cr}_{13} \mathrm{MoV}$ surfacing layer showing less corrosion. Pitting corrosion and intergranular corrosion simultaneously exist in the $8 \mathrm{Cr}_{13}$ surfacing layer (Figure 12c), and the degree of corrosion is higher than the previous two. The corrosion morphologies of the different surfacing layers after electrochemical corrosion testing are basically the same as those of the aforementioned, although that corrosion resistance of the $8 \mathrm{Cr}_{13} \mathrm{MoV}$ surfacing layer is higher than those of the others. 
The results of electrochemical corrosion testing suggest that with an increase in carbon content in the surfacing layer, the corrosion resistance of the surfacing layer markedly decreases. However, Mo and $\mathrm{V}$ can improve the corrosion resistance of the surfacing layer. One reason may be that more $\mathrm{Cr}$ particles are attached to form carbide as the carbon content increases in the same $\mathrm{Cr}$ content of the surfacing layer. Thus, the corrosion resistance of $\mathrm{Cr}$ in the surfacing layer is reduced. However, Mo and V elements are strong carbide-forming elements, and their binding capacity with carbon is stronger than that with $\mathrm{Cr}$ and carbon [43]. The presence of Mo and $\mathrm{V}$ elements can effectively retain the anti-corrosion capacity of $\mathrm{Cr}$ in the surfacing layer. Moreover, the polarization curve in Figure 11 confirms that the $8 \mathrm{Cr}_{13} \mathrm{MoV}$ surfacing layer forms a passive film in the early stages of electrochemical corrosion testing, effectively hindering the corrosion of $\mathrm{Cl}^{-}$on the surface of the surfacing layer [44]. The other reason may be confirmed by Pardo's research that the presence of the Mo element is conducive to the formation of $\mathrm{Mo}^{6+}$ and Mo insoluble compounds with $\mathrm{O}$ in the erosion environment, preventing the erosion of $\mathrm{Cl}^{-}[45,46]$.

\section{Conclusions}

Increasing the carbon content increased the sizes of grains and carbide particles in the stainless steel powder surfacing layer, and weakened the metallurgical bond between the surfacing layer and matrix. However, increasing carbon markedly improved the comprehensive hardness and wear resistance of surfacing layer, slightly increased its impact toughness, but seriously decreased its corrosion resistance.

With the carbon content remaining constant, the presence of Mo and V refined the grain and carbide particles in the stainless steel powder surfacing layer, and positively influenced the metallurgical bond between the surfacing layer and matrix. The presence of Mo and V also contributed to the comprehensive hardness, wear resistance of the surfacing layer, and markedly enhanced its corrosion resistance, but only slightly weakened its impact toughness.

Comprehensive analysis shows that compared with the matrix, the $8 \mathrm{Cr}_{13} \mathrm{MoV}$ surfacing layer has about 1.3 times higher hardness, 3.8 times higher wear resistance, and slightly higher impact toughness. The $8 \mathrm{Cr}_{13} \mathrm{MoV}$ surfacing layer exhibits the same corrosion resistance as that of the matrix and exhibits good metallurgical bonding with the matrix $\left(2 \mathrm{Cr}_{13}\right)$. Therefore, it is a better surfacing material for the edge of knives and scissors.

Author Contributions: Conceptualization, Z.H.; methodology, J.L.; software, X.H.; validation, J.L., X.H. and N.L.; formal analysis, C.W.; investigation, T.X.; resources, C.W.; data curation, T.X.; writing-original draft preparation, T.X.; writing-review and editing, T.X.; visualization, X.H.; supervision, Z.H.; project administration, Z.H. and N.L.; funding acquisition, Z.H. All authors have read and agreed to the published version of the manuscript.

Funding: The authors received financial support from the National Natural Science Foundation of China (No. 51874171), University of Science and Technology Liaoning Talent Project Grants (No. 601011507-05), 2019 joint fund of state key laboratory of metal materials and applications for marine equipment and University of Science and Technology Liaoning (SKLMEA-USTLN-201904), the project of Liaoning Province's “Rejuvenating Liaoning Talents Plan"(XLYC1902092) and the project of Science Department of Liaoning Province(2019-ZD-0273).

Conflicts of Interest: The authors declare no conflict of interest.

\section{References}

1. Deng, D. Present status and development tendency of plasma transferred arc welding. Chin. J. Mech. Eng. 2013, 49, 106-112. [CrossRef]

2. Lindner, T.; Kutschmann, P.; Löbel, M.; Lampke, T. Hardening of HVOF-sprayed austenitic stainless-steel coatings by gas nitriding. Coatings 2018, 8, 348. [CrossRef]

3. Zhu, H.; Li, Y.; Li, B.; Zhang, Z.; Qiu, C. Effects of low-temperature tempering on microstructure and properties of the laser-cladded AISI 420 martensitic stainless steel coating. Coatings 2018, 8, 451. [CrossRef]

4. Pfender, E. Thermal plasma technology: Where do we stand and where are we going? Plasma Chem. Plasma Process. 1999, 19, 1-31. [CrossRef]

5. Deuis, R.L.; Yellup, J.M.; Subramanian, C. Metal-matrix composite coatings by PTA surfacing. Compos. Sci. Technol. 1998, 58, 299-309. [CrossRef] 
6. Kuroda, S.; Fukushima, T.; Kitahara, S. Simultaneous measurement of coating thickness and deposition stress during thermal spraying. Thin Solid Films 1988, 164, 157-163. [CrossRef]

7. Gérard, B. Application of thermal spraying in the automobile industry. Surf. Coat. Technol. 2006, 201, 2028-2031. [CrossRef]

8. Grozdanov, I. Electroless chemical deposition technique for $\mathrm{Cu}_{2} \mathrm{O}$ thin films. Mater. Lett. 1994, 19, $281-285$. [CrossRef]

9. Kyzioł, K.; Oczkowska, J.; Kottfer, D.; Klich, M.; Kaczmarek, Ł.; Kyzioł, A.; Grzesik, Z. Physicochemical and biological activity analysis of low-density polyethylene substrate modified by multi-layer coatings based on DLC structures, obtained using RF CVD method. Coatings 2018, 8, 135. [CrossRef]

10. Baptista, A.; Silva, F.; Porteiro, J.; Míguez, J.; Pinto, G. Sputtering physical vapour deposition (PVD) coatings: A critical review on process improvement and market trend demands. Coatings 2018, 8, 402. [CrossRef]

11. Mattox, D.M. Handbook of Physical Vapor Deposition (PVD) Processing; William Andrew: Burlington, VT, USA, 2010; pp. 1-9.

12. Wang, X.B.; Wang, X.F.; Shi, Z.Q. The composite Fe-Ti-B-C Coatings by PTA powder surfacing process. Surf. Coat. Technol. 2005, 192, 257-262.

13. Liu, Y.F.; Xia, Z.Y.; Han, J.M.; Zhang, G.L.; Yang, S.Z. Microstructure and wear behavior of $(\mathrm{Cr}, \mathrm{Fe})_{7} \mathrm{C}_{3}$ reinforced composite coating produced by plasma transferred arc weld-surfacing process. Surf. Coat. Technol. 2006, 201, 863-867. [CrossRef]

14. Xie, G.Z.; Song, X.L.; Zhang, D.J.; Wu, Y.P.; Lin, P.H. Microstructure and corrosion properties of thick WC composite coating formed by plasma cladding. Appl. Surf. Sci. 2010, 256, 6354-6358.

15. Kim, Y.J. Wear and corrosion resistance of PTA weld surfaced Ni and Co based alloy layers. Surf. Eng. 1999, 15, 495-501. [CrossRef]

16. Yükse, N.; Şahin, S. Wear behavior-hardness-microstructure relation of $\mathrm{Fe}-\mathrm{Cr}-\mathrm{C}$ and $\mathrm{Fe}-\mathrm{Cr}-\mathrm{C}-\mathrm{B}$ based hardfacing alloys. Mater. Des. 2014, 58, 491-498. [CrossRef]

17. Liu, R.M.; Yao, M.X.; Patnaik, P.C.; Wu, X.J. An improved wear-resistant PTA hardfacing: VWC/Stellite 21. J. Compos. Mater. 2006, 40, 2203-2215. [CrossRef]

18. Azimi, G.; Shamanian, M. Effects of silicon content on the microstructure and corrosion behavior of $\mathrm{Fe}-\mathrm{Cr}-\mathrm{C}$ hardfacing alloys. J. Alloys Compd. 2010, 505, 598-603. [CrossRef]

19. Wang, Y.; Chen, J.; Yang, J.; Hao, F.; Dan, T.; Yang, Y.; Yang, Q. Effect of $\mathrm{La}_{2} \mathrm{O}_{3}$ on granular bainite microstructure and wear resistance of hardfacing layer metal. J. Rare Earths 2014, 32, 83-89. [CrossRef]

20. Klimpel, A.; Dobrzański, L.A.; Lisiecki, A.; Janicki, D. The study of the technology of laser and plasma surfacing of engine valves face made of $\mathrm{X} 40 \mathrm{CrSiMo10-2}$ steel using cobalt-based powders. J. Mater. Process. Technol. 2006, 175, 251-256. [CrossRef]

21. Gladkii, P.V.; Perepletchikov, E.F.; Ryabtsev, I.A. Plasma surfacing. Weld. Int. 2007, 21, 685-693. [CrossRef]

22. Bogolyubskii, S.D.; Guk, V.V.; Shlyamnev, A.P. Corrosion resistance of knife steels. J. Mater. Process. Technol. 2001, 43, 267-269.

23. Udod, K.A.; Rodionova, I.G.; Knyazev, A.V.; Stukalin, S.V. Study of the effect of chemical composition and heat treatment on corrosion resistance indices for martensitic class stainless steels alloyed with nitrogen. Metallurgist 2016, 59, 1096-1100. [CrossRef]

24. Prieto, G.; Tuckart, W.R. Influence of cryogenic treatments on the wear behavior of AISI 420 martensitic stainless steel. J. Mater. Eng. Perform. 2017, 26, 5262-5271. [CrossRef]

25. Qiuli, Z.; Hong, S.; Haiyan, W.; Erwei, C. Brief introduction to metallic materials charpy impact testing method of GB/T 229-2007. Phys. Test. Chem. Anal. 2010, 46, 190-192.

26. Jiaxiang, C. Data Sheets for Common Steelmaking Charts; Metallurgical Industry Press: Beijing, China, 1984; pp. 155-162.

27. Gulyaev, A.P.; Sergienko, L.P. Effect of molybdenum and vanadium on the structure and properties of tungstenless high-speed powder steel. Met. Sci. Heat Treat. 1986, 28, 112-118. [CrossRef]

28. Todić, A.; Čikara, D.; Todić, T.; Pejović, B.; Mišić, M.; Čamagić, I. The effect of vanadium content on mechanical properties and structure of self-hardening steel X160CrMo12-1. J. Mech. Eng. Autom. 2013, 3, 168-172.

29. Dilawary, S.A.; Motallebzadeh, A.; Houdková, Š.; Medlin, R.; Haviar, S.; Lukáč, F.; Afzal, M.; Cimenoglu, H. Modification of M2 hardfacing: Effect of molybdenum alloying and laser surface melting on microstructure and wear performance. Wear 2018, 404, 111-121. [CrossRef] 
30. Gao, Y.; Gao, Q.; Xu, J.Y.; Liao, H.Y. Morphology and composition of plasma alloying of Cr-Mo layer. Surf. Coat. Technol. 2007, 201, 5526-5528. [CrossRef]

31. Hajihashemi, M.; Shamanian, M.; Azimi, G. Physical, Mechanical, and dry sliding wear properties of Fe-Cr-W-C hardfacing alloys under different tungsten addition. Metall. Mater. Trans. B 2015, 46, 919-927. [CrossRef]

32. Hemmati, I.; Ocelík, V.; De Hosson, J.T.M. Dilution effects in laser cladding of Ni-Cr-B-Si-C hardfacing alloys. Mater. Lett. 2012, 84, 69-72. [CrossRef]

33. Liljedahl, C.D.; Zanellato, O.; Fitzpatrick, M.E.; Lin, J.; Edwards, L. The effect of weld residual stresses and their re-distribution with crack growth during fatigue under constant amplitude loading. Int. J. Fatigue 2010, 32, 735-743. [CrossRef]

34. Labeas, G.; Diamantakos, I. Numerical investigation of through crack behaviour under welding residual stresses. Eng. Fract. Mech. 2009, 76, 1691-1702. [CrossRef]

35. Sevim, I.; Eryurek, I.B. Effect of fracture toughness on abrasive wear resistance of steels. Mater. Des. 2006, 27, 911-919. [CrossRef]

36. Modi, O.P.; Mondal, D.P.; Prasad, B.K.; Singh, M.; Khaira, H.K. Abrasive wear behaviour of a high carbon steel: Effects of microstructure and experimental parameters and correlation with mechanical properties. Mater. Sci. Eng. A 2003, 343, 235-242. [CrossRef]

37. Su, Y.L.; Chen, K.Y. The influence of niobium, chromium, molybdenum and carbon on the sliding wear behavior of nickel-base hardfacing alloys. Wear 1997, 209, 160-170. [CrossRef]

38. Qi, X.; Jia, Z.; Yang, Q.; Yang, Y. Effects of vanadium additive on structure property and tribological performance of high chromium cast iron hardfacing metal. Surf. Coat. Technol. 2011, 205, 5510-5514. [CrossRef]

39. Fang, X.; Cao, R.; Li, G.; Jiang, F.; Chen, J. Effects of grain sizes and second phase sizes of 16MnR steel on its low temperature impact toughness. Chin. J. Mech. Eng. 2011, 47, 40-44. [CrossRef]

40. Wu, M.W.; Tsao, L.C.; Shu, G.J.; Lin, B.H. The effects of alloying elements and microstructure on the impact toughness of powder metal steels. Mater. Sci. Eng. A 2012, 538, 135-144. [CrossRef]

41. Kong, J.H.; Zhen, L.; Guo, B.; Li, P.H.; Wang, A.H.; Xie, C.S. Influence of Mo content on microstructure and mechanical properties of high strength pipeline steel. Mater. Des. 2004, 25, 723-728.

42. Ranganatha, S.; Venkatesha, T.V.; Vathsala, K. Electrochemical studies on Zn/nano-CeO 2 electrodeposited composite coatings. Surf. Coat. Technol. 2012, 208, 64-72. [CrossRef]

43. Cui, Z.Q.; Liu, B.X. Principles of Metallurgy and Heat Treatment; Harbin Institute of Technology: Harbin, China, 2004; pp. 56-99.

44. Calliari, I.; Zanesco, M.; Dabala, M.; Brunelli, K.; Ramous, E. Investigation of microstructure and properties of a Ni-Mo martensitic stainless steel. Mater. Des. 2008, 29, 246-250. [CrossRef]

45. Pardo, A.; Merino, M.C.; Coy, A.E.; Viejo, F.; Arrabal, R.; Matykina, E. Effect of Mo and Mn additions on the corrosion behaviour of AISI 304 and 316 stainless steels in $\mathrm{H}_{2} \mathrm{SO}_{4}$. Corros. Sci. 2008, 50, 780-794. [CrossRef]

46. Pardo, A.; Merino, M.C.; Coy, A.E.; Viejo, F.; Arrabal, R.; Matykina, E.J. Pitting corrosion behaviour of austenitic stainless steels-combining effects of Mn and Mo additions. Corros. Sci. 2008, 50, 1796-1806. [CrossRef]

(C) 2020 by the authors. Licensee MDPI, Basel, Switzerland. This article is an open access article distributed under the terms and conditions of the Creative Commons Attribution (CC BY) license (http://creativecommons.org/licenses/by/4.0/). 